\title{
Analysis of Relationships between Altitude and Distance from Volcano with Stomach Cancer Incidence Using a Geographic Information System
}

\author{
F Amani ${ }^{1}$, S Sadeghieh Ahari², S Barzegari ${ }^{3 *}$, B Hassanlouei ${ }^{4}$, M Sadrkabir ${ }^{5}$, \\ Esmaeil Farzaneh ${ }^{6}$
}

\begin{abstract}
Gastric cancer (GC) is the fifth most common cancer in the world, with a wide variation in incidence rates across different geographical areas. In Iran GC is the most common cancer in males and it is reported to be the third most prevalent after breast and colorectal in females. A geographical information system (GIS) allows investigation of the geographical distribution of diseases. The purpose of the present study was to explore the relationship between gastric cancer and effective climatic factors using GIS. The dispersion distribution and the relationship between environmental factors effective on cancer were measured using Arc GIS. Of all cases, $672(73.8 \%)$ were in males with a sex ratio of 3 to1. The highest incidence by cities was seen in Namin with 137.5 per 100,000 . The results of this study showed that the distribution of GC around the Sabalan volcanic mountain was significantly higher than other places in the same province. These results can be considered as a window to future comprehensive research on gastric cancer.
\end{abstract}

Keywords: Gastric cancer - geographical information system - incidence - environmental factors - Iran

Asian Pac J Cancer Prev, 16 (16), 6889-6894

\section{Introduction}

According to the estimations of the International Agency for Research on Cancer (IARC) in 2012, gastric cancer is the fifth most common cancer in the world (Kavousi et al., 2014), with a wide variation in incidence rates across different geographical areas. In Iran gastric cancer is the most common cancer in male and it is reported to be the third cancer after Breast and Colorectal cancers in female (Babaei et al., 2010). According to GLOBOCAN, gastric cancer in Iran accounted for $11.4 \%$ of all cases of cancer occurrence and the second most prevalent cancer and also most deadly cancer with 15.5 percent of all mortalities caused by cancers (Ferley et al., 2012). Ardabil is still one of the areas in the world that has the highest incidence of gastric cancer (Babaei et al., 2010; Sadjadi et al., 2003). Recently, the incidence and mortality rate of gastric cancer has dramatically fallen worldwide. In line with global reduction, the incidence rate of cancer has decreased in Asia as well. However, the incidence of gastric cancer in Iran remains very high at approximately 26.1 per 100, 000 (Rahman et al., 2014). In most countries there is a steady decline in the incidence and mortality from gastric cancer. However in the United States, like
Iran, gastric cancer remains on the list of cancers that have a high mortality and is the reason for $2 \%$ of all deaths from cancer (Kasper et al., 2005).

Various risk factors for stomach cancer, such as smoking, nutrition and infection with Helicobacter pylori has been identified, but other factors such as geography and ethnicity also appears to be effective against the disease.

Despite the decline in the incidence of gastric cancer in the world but still in a developed country such as Japan and developing country such as Iran this rate is up and in fact, this reduction cannot be seen in some geographic areas.

On the other hand, the results of several studies have shown that the incidence of gastric cancer in volcanic regions, highland (such as Japan) is higher than other regions (Jesiis et al., 1995; Dogan et al., 2009; Javier et al., 2013; Junko et al., 2014). Ardabil and East Azerbaijan provinces have these features and the dormant volcano Mount Sabalan was located in Ardabil province and Sahand in East Azerbaijan province.

According to higher rate of mortality and gastric cancer incidence in two provinces, it seems that some geographic factors were effective in cancer incidence. So, the aim of this study was to investigate the relationship between the

${ }^{1}$ Biostatistics, ${ }^{2}$ Community Medicine, ${ }^{5}$ Internal Medicine, ${ }^{5}$ Department of Forensic Medicine and Toxicology, Ardabil University of Medical Sciences, Ardabil, ${ }^{3}$ Department of Epidemiology, School of Public Health, Iran University of Medical Sciences, Tehran, ${ }^{4}$ Amol Faculty of Paramedical Sciences, Mazandaran University of Medical Sciences, Sari, Iran *For correspondence: ssbarzegari@ mazums.ac.ir 
height and proximity to the volcanic mountains and the incidence of gastric cancer.

\section{Materials and Methods}

The study area

Ardabil province is located at $37^{\circ} 9^{\prime} 21^{\prime \prime}-39^{\circ} 42^{\prime} 32^{\prime \prime}$ northern geographical latitude and $47^{\circ} 1^{\prime} 51^{\prime \prime}-48^{\circ} 54^{\prime} 7^{\prime \prime}$ eastern geographical longitude bordering south side of Aras River, east and south of eastern Azerbaijan and west part of gilan province and Azerbaijan Republic. Ardabil province has the 23 th rank among 34 provinces of Iran considering human development. As it can be seen in map 1, this province encompasses $17,800 \mathrm{~km} 2$ including 10 towns and 537 villages. According to census in 2012, Ardabil is a province with population of 1.248 million and population density of 70 per $\mathrm{km} 2$ (Statistical center of Iran, 2012). The majority of the population (more than $98 \%)$ is of Azeri ethnicity.

\section{Study design and study population}

This is a cross-sectional descriptive study and the statistical population included all registered gastric cancer patients in Ardabil about 1056 patients within March 2003 to September 2011. The participants were collected using documents and files available in cancer registry center (Aras) in Ardabil Imam Khomeini hospital. Because of non-exact location address in some patient's files, we used 910 patient's information in statistical analysis of data and GIS maps.

\section{Data collection and analysis}

From documents and records in the cancer registry in Imam Khomeini Hospital of Ardabil necessary information such as gender, occupation, age and place of residence and the exact address location were extracted. Collected data analyzed by statistical methods in SPSS.19 and also in Arc view GIS 10 for presentation the distribution of cancer cases.

\section{Statistical analysis}

We obtained the Latitude and longitude location of each patient by Google earth and then transferred to the Arc view GIS 10.1 software. The hot spot and Spatial autocorrelation (Moran's I) was done for distribution of patients and classified the patients in Buffers with $10 \mathrm{~km}$ from Sabalan Volcano in height $400 \mathrm{~m}$. The incidence of gastric cancer in different height and distance classes according to the population and patients of each class calculated by GIS software. We used linear regression analysis with the software package SPSS.19 for investigation the relationship between height, distance from the volcano, and other factors with incidence of gastric cancer.

Table 1. Incidence of Gastric Cancer by Residence Place in Cities

\begin{tabular}{|c|c|c|c|c|c|c|c|c|c|}
\hline City & Population & Pop_R & Pop_U & Patient & Patient_R & Patient_U & Incidence & Inciden_R & Inciden_U \\
\hline Ardabil & 567361 & 61692 & 505669 & 352 & 173 & 179 & 0.62 & 2.804 & 0.353 \\
\hline Sarein & 30188 & 11988 & 18200 & 28 & 24 & 4 & 0.927 & 2.002 & 0.219 \\
\hline Namin & 70524 & 46316 & 24208 & 97 & 73 & 24 & 1.375 & 1.576 & 0.991 \\
\hline Germi & 86820 & 53712 & 33108 & 90 & 71 & 19 & 1.036 & 2.144 & 0.573 \\
\hline BilaSuvar & 51812 & 31336 & 20476 & 60 & 47 & 13 & 1.158 & 1.499 & 0.634 \\
\hline Meshgin & 162980 & 89373 & 73607 & 129 & 97 & 32 & 0.791 & 1.085 & 0.434 \\
\hline Nir & 25420 & 18800 & 6620 & 29 & 20 & 9 & 1.14 & 1.063 & 1.359 \\
\hline Kosar & 29246 & 20670 & 8576 & 21 & 15 & 6 & 0.718 & 0.725 & 0.699 \\
\hline Khalkhal & 106771 & 51760 & 55011 & 59 & 35 & 24 & 0.552 & 0.676 & 0.436 \\
\hline Parsabad & 161115 & 68848 & 92267 & 45 & 30 & 15 & 0.279 & 0.435 & 0.162 \\
\hline All & 1292237 & 454495 & 837742 & 910 & 585 & 325 & 0.704 & 1.287 & 0.387 \\
\hline
\end{tabular}

Table 2. Distribution of Gastric Cancer by Altitude

\begin{tabular}{|c|c|c|c|c|c|c|c|c|}
\hline \multicolumn{9}{|c|}{ Altitude } \\
\hline & $0-400$ & 800 & 1200 & 1600 & 2000 & 2400 & 2800 & 4800 \\
\hline Population & 214400 & 61198 & 64399 & 764875 & 140344 & 15380 & 344 & 0 \\
\hline Pop_City & 119168 & 25460 & 7055 & 593907 & 53408 & 0 & 0 & 0 \\
\hline Pop_Village & 95232 & 35738 & 57344 & 170968 & 86936 & 15380 & 344 & 0 \\
\hline Patient & 97 & 52 & 66 & 514 & 155 & 25 & 1 & 0 \\
\hline P_City & 28 & 5 & 16 & 240 & 36 & 0 & 0 & 0 \\
\hline P_Village & 69 & 47 & 50 & 274 & 119 & 25 & 1 & 0 \\
\hline Incidence & 0.452 & 0.85 & 1.02 & 0.672 & 1.1 & 1.62 & 2.9 & 0 \\
\hline In_City & 0.234 & 0.196 & 2.267 & 0.404 & 0.674 & 0 & 0 & 0 \\
\hline In_Village & 0.724 & 1.315 & 0.871 & 1.602 & 1.368 & 1.625 & 2.906 & 0 \\
\hline Area & 2552.1 & 1592.7 & 2285.7 & 5177.6 & 3403.9 & 714.2 & 223.2 & 176.3 \\
\hline Cardia_Incidence & 0.219 & 0.408 & 0.543 & 0.266 & 0.391 & 0.78 & 2.9 & 0 \\
\hline Fundus_Incidence & 0.21 & 0.343 & 0.357 & 0.31 & 0.463 & 0.78 & 2.9 & 0 \\
\hline Antrum_Incidence & 0.093 & 0.18 & 0.279 & 0.18 & 0.37 & 0.39 & 0 & 0 \\
\hline
\end{tabular}




\section{Results}

Of all cases, 672(73.8\%) were male and rest of them were female with sex ratio 3 to 1 . The incidence of gastric cancer by cities and residence place were in Table 1 .

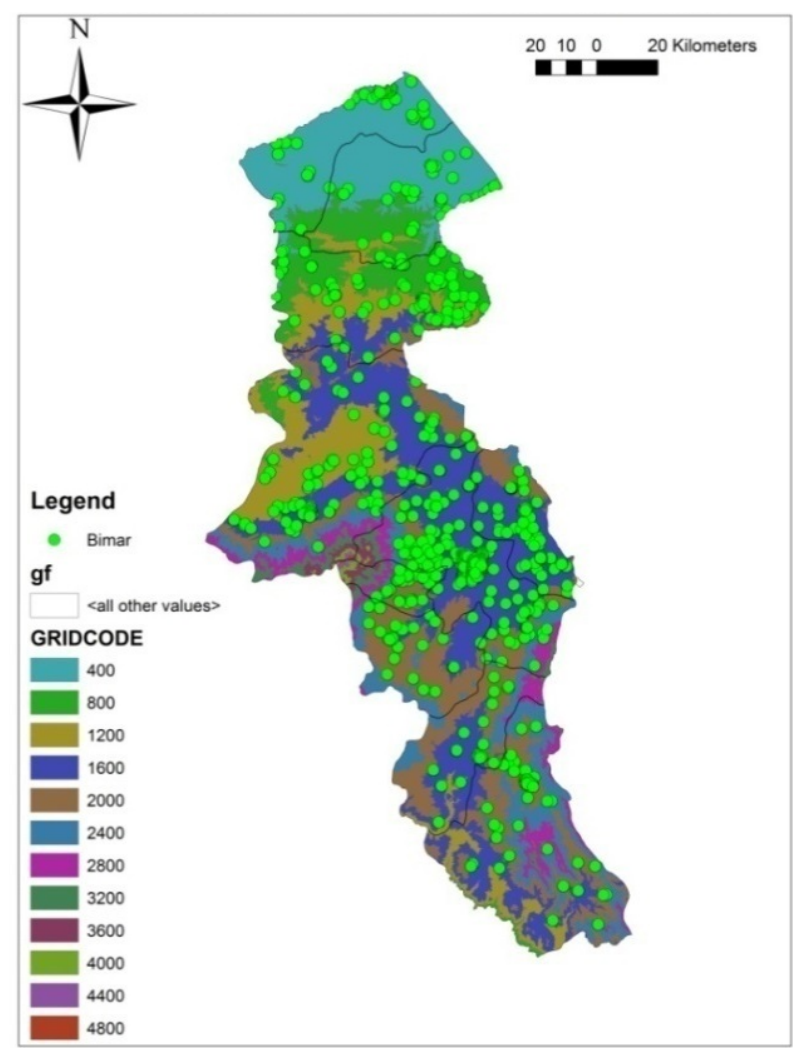

Figure 1. Distribution of Gastric Cancer by Altitude in Ardabil Province

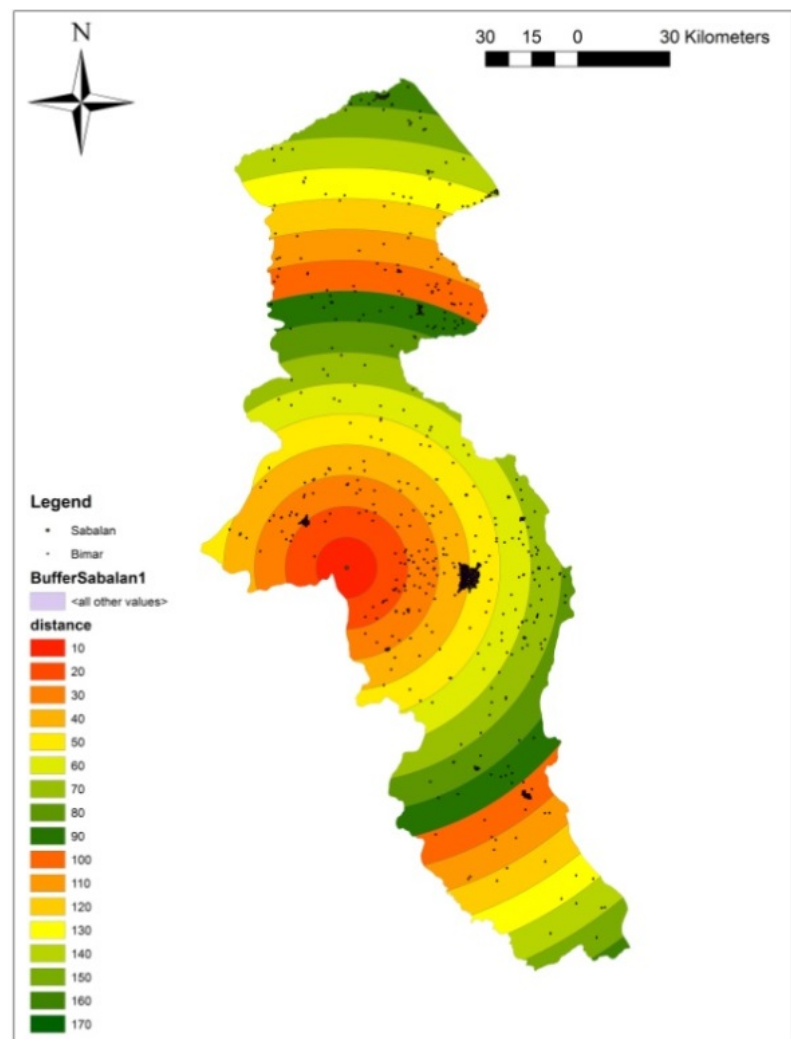

Figure 2. Distribution of Gastric Cancer by Distance From Sabalan Volcano in Ardabil Province
With replace cancer cases on Ardabil province elevation map (Figure 1) and produce the height classes in $400 \mathrm{~m}$, the results were in Table 2. Also created a buffer of 10 kilometers of volcanic mountains and add descriptive data on the map (Figure 2), the result of table 3 was obtained.

The results of hot spot and Spatial autocorrelation (Moran's I) analysis by Arc GIS software is presented in Figures 3 and 4.

The hot spot and Spatial autocorrelation (Moran's I) analysis can be observe the regular and irregular of diseases in one location and the effect of factors on diseases. The map produced by GiZScore. The irregular and cluster distribution of gastric cancer in areas of the province of Ardabil. To extract some hidden data on the map and to improve understanding of map hot spots, IDW interpolation was used. (Figure 5)

The distribution of hot spots suggests that the closer to the volcano the people live the denser involvement with the cancer is observed. We used from linear regression method for study relationship between highest and GC

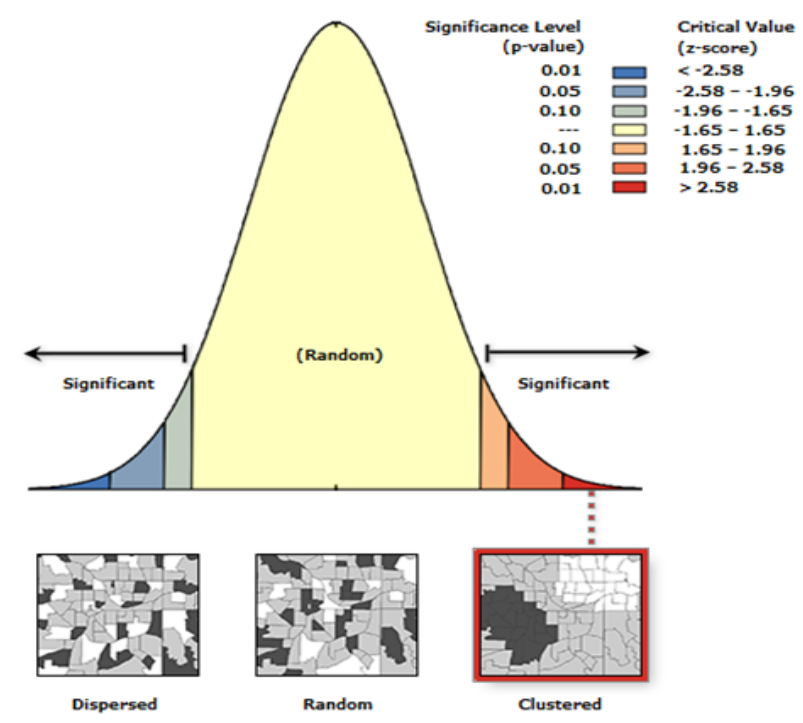

Figure 3. Spatial Autocorrelation (Moran's I) Analysis of GC in Ardabil Province

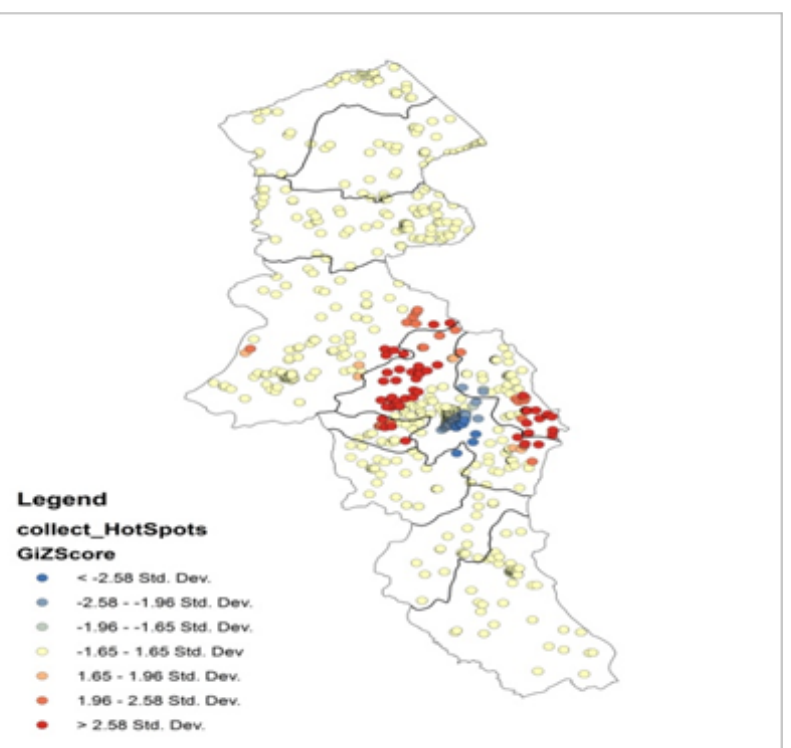

Figure 4. Hot Spot Analysis of GC in Ardabil 
Table 3. Distribution of Gastric Cancer by Distance from Sabalan Volcano

\begin{tabular}{|c|c|c|c|c|c|c|c|c|}
\hline $\begin{array}{c}\text { Distance } \\
\text { From Sabalan Volcano }\end{array}$ & 10 & 20 & 30 & 40 & 50 & 60 & 70 & 80 \\
\hline Population & 104 & 41644 & 133577 & 345992 & 243103 & 50783 & 52430 & 29558 \\
\hline Pop- City & 0 & 26104 & 68945 & 297164 & 208871 & 17967 & 5922 & 7158 \\
\hline Pop_Village & 104 & 15540 & 64632 & 48828 & 34232 & 32816 & 46508 & 22400 \\
\hline Patient & 0 & 38 & 138 & 176 & 119 & 78 & 86 & 25 \\
\hline Patient_City & 0 & 12 & 23 & 109 & 72 & 17 & 15 & 6 \\
\hline Patient_Village & 0 & 26 & 115 & 67 & 47 & 61 & 71 & 19 \\
\hline Incidence & 0 & 0.912 & 1.033 & 0.508 & 0.489 & 1.535 & 1.64 & 0.845 \\
\hline In_City & 0 & 0.459 & 0.333 & 0.366 & 0.344 & 0.946 & 2.532 & 0.838 \\
\hline In_Village & 0 & 1.673 & 1.779 & 1.372 & 1.372 & 1.858 & 1.526 & 0.848 \\
\hline Cardia_Incidence & 0 & 0.384 & 0.389 & 0.19 & 0.213 & 0.649 & 0.762 & 0.202 \\
\hline Fundus_Incidence & 0 & 0.504 & 0.471 & 0.239 & 0.23 & 0.571 & 0.781 & 0.338 \\
\hline Antrum_Incidence & 0 & 0.216 & 0.254 & 0.124 & 0.123 & 0.472 & 0.534 & 0.372 \\
\hline Area & 287.8 & 762 & 1236.3 & 1612.4 & 1653.4 & 1746.3 & 1583.9 & 1196.7 \\
\hline $\begin{array}{c}\text { Distance } \\
\text { From Sabalan Volcano } \\
\end{array}$ & 90 & 100 & 110 & 120 & 130 & 140 & 150 & 160 \\
\hline Population & 61009 & 78993 & 26226 & 12296 & 31807 & 55111 & 27933 & 108352 \\
\hline Pop- City & 31497 & 41165 & 4578 & 0 & 3875 & 25263 & 2797 & 88924 \\
\hline Pop_Village & 29512 & 37828 & 21648 & 12296 & 27932 & 29848 & 25136 & 19428 \\
\hline Patient & 53 & 71 & 23 & 15 & 32 & 22 & 11 & 23 \\
\hline Patient_City & 19 & 22 & 2 & 0 & 4 & 9 & 2 & 13 \\
\hline Patient_Village & 34 & 49 & 21 & 15 & 28 & 13 & 9 & 10 \\
\hline Incidence & 0.868 & 0.898 & 0.876 & 1.219 & 1.006 & 0.399 & 0.393 & 0.212 \\
\hline In_City & 0.603 & 0.534 & 0.436 & 0 & 1.032 & 0.356 & 0.715 & 0.146 \\
\hline In_Village & 1.152 & 1.295 & 0.97 & 1.219 & 1.002 & 0.435 & 0.358 & 0.514 \\
\hline Cardia_Incidence & 0.409 & 0.367 & 0.343 & 0.406 & 0.471 & 0.217 & 0.286 & 0.101 \\
\hline Fundus_Incidence & 0.278 & 0.303 & 0.381 & 0.569 & 0.534 & 0.181 & 0.178 & 0.101 \\
\hline Antrum_Incidence & 0.278 & 0.291 & 0.305 & 0.406 & 0.157 & 0.09 & 0 & 0.027 \\
\hline Area & 1199.6 & 1208.5 & 1081 & 996.1 & 1119 & 1189.4 & 718.6 & 209 \\
\hline
\end{tabular}

\section{Table 4. Result's of linear regression Analysis}

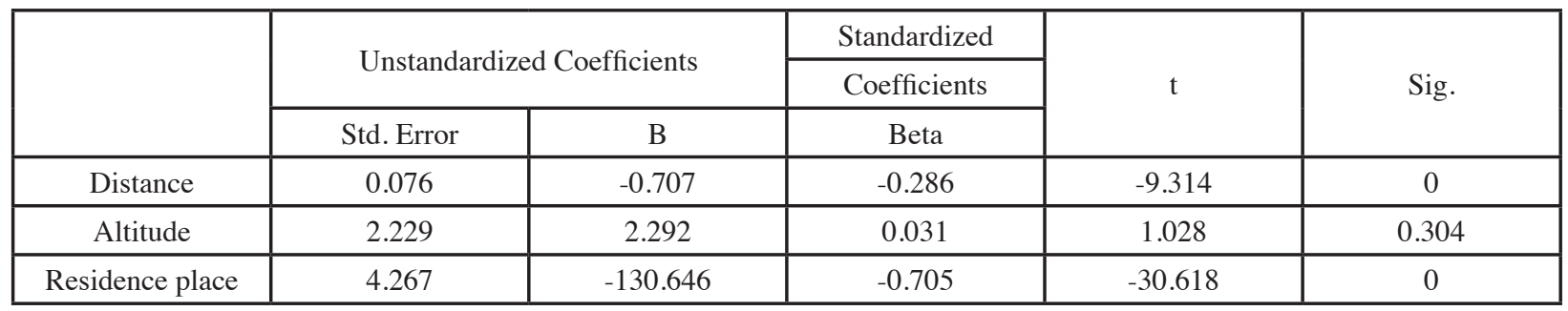

incidence. The results showed that there was a significant indirect relationship between distance to Sabalan with GC incidence, means that proximity to the volcano Sabalan increases the incidence of gastric cancer. It was found that the rate of GC in people from rural areas significantly higher than people from Urban areas. (Table 4)

\section{Discussion}

In this study according table 3 , the mean incidence rate in distance $70 \mathrm{~km}$ from Sabalan with 70 per 100000 significantly higher than distance $70-160 \mathrm{~km}$ from Sabalan with 64 per $100000 .(\mathrm{OR}=0.8, \mathrm{P}=0.0018)$

Akan et al in a study showed that there was a significant relationship between cancer cases and environmental radioactivity. In this study, the higher GC incidence rate was seen in distance 50-70 km from Sabalan exactly around the Namin, Meshkinshahr and part of Ardabil which probably can be related to higher radiation of radioactive materials and volcanic soil type. The results show a high incidence of gastric cancer hypothesis in kilometers closer to Sabalan than longer distances can be 


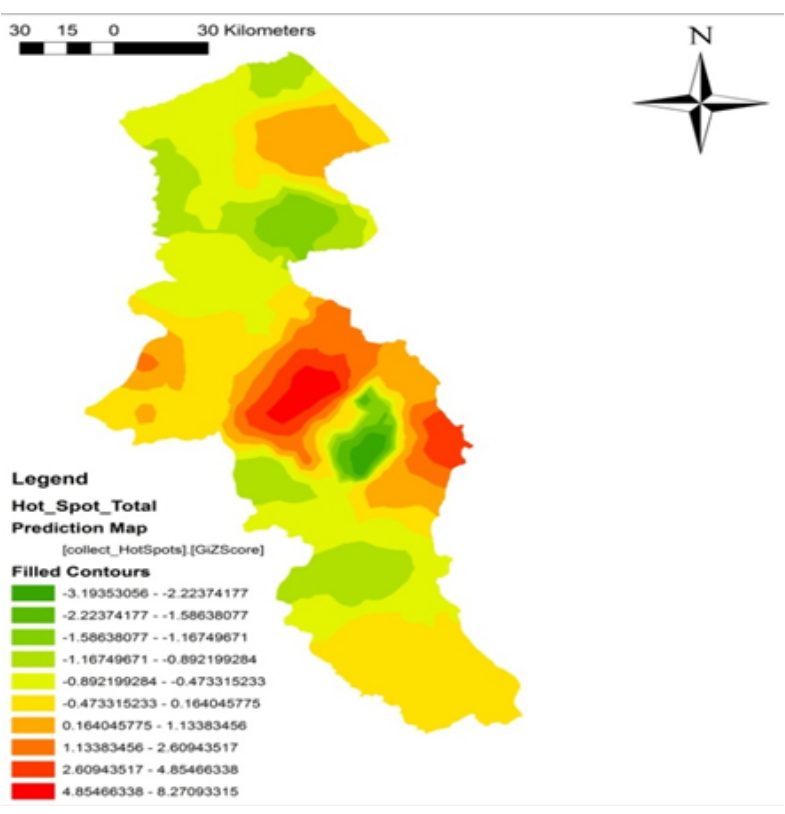

Figure 5. IDW Analysis of GC in Ardabil Province (Red dots indicate the hot spot areas and the blue dots indicate cold spots)

accepted (Akan et al., 2014).

In a study done in Chile about Urea nitrate and incidence rate of $\mathrm{GC}$, results showed that despite the hypothesis that high nitrate due to stomach cancer, Nitrate concentration was higher in areas with a low risk of cancer which suggest the possibility of environmental cofactors involved in the conversion of nitrate to nitrosamine as a factor in gastric cancer. Also, in Chile study in the area with higher incidence rate the soil similar to soil of volcanic areas and contains high levels of Arsenic and low levels of selenium that could cause the conversion of nitrate to nitrous amines (Armijo et al., 1981).

Agustin et al in studies showed that more than $95 \%$ of countries with high level of digestive cancers, lymphoma, Leukemia and childhood cancers were in areas with radioactive materials and heavy metals such as copper, lead and cadmium (Amarel et al., 2006).

In our study, the rate of cancer in rural people was higher than urban people (64.3\% v.s $35.7 \%$ ) which weren't similar to other studies. These differences may represent the effect of other known or unknown environmental risk factors such as life style, agricultural poisoning and personal behaviors (Davoodabadi et al., 2003; Yazdanbod et al., 2007).

Of all cases, $73.8 \%$ were male and $26.2 \%$ were female and the sex ration 3 to 1 which was similar to other studies (Nourinayer et al., 2005; Yazdanbod et al., 2007). Also, in this study $42 \%$ of patients were farmer which was similar to other studies (Yazdanbod et al., 2007).

In our investigation $64.3 \%$ of patients were from rural, $80.9 \%$ Illiterate and $53.2 \%$ farmer and the rate of cancer incidence in low social economic levels were high which was similar to other study (Babaei et al., 2009; Ahari SS., 2013; Amorim et al., 2014).

The results of this study showed that the distribution of $\mathrm{GC}$ around the Sabalan volcanic mountain is significantly higher than other places in province, therefore, we can accept the hypothesis of increased incidence of gastric cancer in areas near the volcanic mountain. But the influence of other risk factors such as smoking and lifestyle should not be ignored.

\section{Acknowledgements}

The authors would like to acknowledge all persons help us. This study was supported financially by the Faculty of Medicine, Ardabil University of Medical Science.

\section{References}

Akan Z, Baskurt B, Asliyuksek H, et al (2014). Environmental radioactivity and high incidence rates of stomach and esophagus cancer in the Van Lake region: a causal relationship? Asian Pac J Cancer Prev, 15, 375-80.

Amarel A, Rodirgues V, Oliveria J, et al (2006). Chronic exposure to volcanic environments and cancer incidence in the Azores, Portugal. Sci Total Environ, 37, 123-8.

Amorim CA, Moreira JP, Rial L, Carneiro AJ, Fogaça HS, Elia $\mathrm{C}$, et al (2014). Ecological study of gastric cancer in Brazil: Geographic and time trend analysis. World J Gastroenterol, 20, 5036-44.

Armijo R, Gonzalez A, Orellana M, Coulson AH, Sayre JW, Detels R (1981). Epidemiology of gastric cancer in chile: Nitrate exposures and stomach cancer frequency. In $J$ Epidemiol, 10, 57-62.

Babaei M, Pourfarzi F, Yazdanbod A, et al (2010). Gastric cancer in Ardabil, Iran - a review and update on cancer registry data. Asian Pac J Cancer Preve, 11, 595-9.

Davood Abadi AH, Sharifi H, Erfan N, Dianati M, Abdol Rahim Kashi E (2003). AN Epidemiologic and clinical survey on gastric cancer patients refered to shahid beheshti hospital of Kashan (1994-2001). IJMS, 34, 211-22.

Dogan Nasır Binici, Timur Koca, Hakan Dursun (2009). Dietary habits, demographical, and socio-economical risk factors of the newly diagnosed gastric cancers in the eastern anatolia region of turkey: an endemic upper gastrointestinal cancer region. Dig Dis Sci, 54, 2629-33.

Ferlay J, Soerjomataram I, Ervik M, et al (2013). GLOBOCAN 2012 v1.0, cancer incidence and mortality worldwide: iarc cancer base No. 11 [Internet]. Lyon, france: international agency for research on cancer. Available from http:// globocan.iarc.fr.

Javier Torres, Pelayo Correa, Catterina Ferreccio, et al (2013). Gastric cancer incidence and mortality is associated with altitude in the mountainous regions of pacific latin America. Cancer Causes Control, 24, 249-56.

Jesiis Vloque, Cayetano Merino Egea, Miquel Porta (1995). Stomach cancer mortality in Spain: an ecological analysis of diet, altitude, latitude, and income. J Epidemiol Community Health, 49, 441-2.

Junko Ueda, Masahiko Gosho, Yoshikatsu Inui, et al (2014). Prevalence of helicobacter pylori infection by birth year and geographic area in Japan. Helicobacter, 19, 105-10

Kasper DL, Braunwald E, Hauser S (2005). Harrison's principles of internal medicine. $16^{\text {th }}$ ed. Mcgraw-Hill: London; 2005, 523-32.

Kavousi A, Bashiri Y, Mehrabi Y, Etemad K, Teymourpour A (2014). Identifying high-risk clusters of gastric cancer incidence in Iran, 2004 - 9. Asian Pac J Cancer Prev, 15, 10335-7.

Masoud Babaei, Hamid Jaffarzadeh, Malekzadeh Reza, et al 
(2009).cancer incidence and mortality in Ardabil: The first report of angoing population based cancer registry in Iran. Iranian J Public Health, 38, 35-45.

Nourinayer B, Akhondi Sh, Asadzadeh H, et al (2005). Evaluation of gastric cancer related indicators in Tehran and 7 other provinces in, 1999 and 2000. Med Sci J Islamic Azad University, 15, 15-18.

Rahman R, Asombang AW, Ibdah JA (2014). Characteristics of gastric cancer in Asia. World J Gastroenterol, 28, 4483-90.

Sadjadi A, Makekzadeh R, Derakhshani M, Sepehr A, Nouraei $\mathrm{M}$, et al (2003). Cancer occurrence in ardabil: results of a population-based cancer registry from Iran. Int J Cancer, 107, 113-18.

Sadeghiyeh-Ahari S, Agdam FB, Amani F, Yazdanbod A, Akhghari L (2013). Analysis of the relationships between esophageal cancer cases and climatic factors using a Geographic Information System (GIS): a case study of Ardabil province in Iran. Asian Pac J Cancer Prev, 14, 2071-7.

Yazdanbod A, Malekzadeh R (2007). Epidemiology of upper gastro intestinal Cancers in Iran: A subsite Analysis of 767 cases. World J Gastroenterol, 13, 5367-70. 